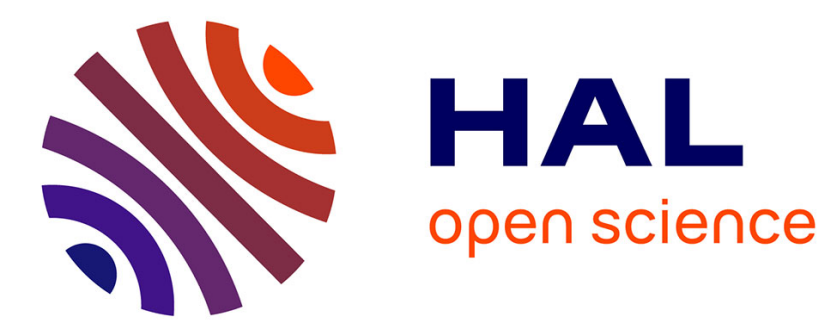

\title{
Bowtie-shaped nanoaperture: a modal study
}

I. Abdoulkader Ibrahim, Mathieu Mivelle Mivelle, T. Grosjean, J.-T. Allegre, G.W. Burr, F.I. Baida

\section{To cite this version:}

I. Abdoulkader Ibrahim, Mathieu Mivelle Mivelle, T. Grosjean, J.-T. Allegre, G.W. Burr, et al.. Bowtie-shaped nanoaperture: a modal study. Optics Letters, 2010, 35 (14), pp.2448-2450. 10.1364/OL.35.002448 . hal-00517018

\section{HAL Id: hal-00517018 \\ https://hal.science/hal-00517018}

Submitted on 18 Apr 2021

HAL is a multi-disciplinary open access archive for the deposit and dissemination of scientific research documents, whether they are published or not. The documents may come from teaching and research institutions in France or abroad, or from public or private research centers.
L'archive ouverte pluridisciplinaire HAL, est destinée au dépôt et à la diffusion de documents scientifiques de niveau recherche, publiés ou non, émanant des établissements d'enseignement et de recherche français ou étrangers, des laboratoires publics ou privés. 


\title{
Bowtie-shaped nanoaperture: a modal study
}

\author{
I. A. Ibrahim, ${ }^{1}$ M. Mivelle, ${ }^{1}$ T. Grosjean, ${ }^{1}{ }{ }-$ T. Allegre,${ }^{2}$ G. W. Burr, ${ }^{2}$ and F. I. Baida ${ }^{1, *}$ \\ ${ }^{1}$ Institut Franche-Comté Electronique, Mécanique, Thermique et Optique - Sciences et Technologies (FEMTO-ST), UMR 6174 \\ CNRS, Département d'Optique P. M. Duffieux, Université de Franche-Comté, 25030 Besançon Cedex, France \\ ${ }^{2}$ IBM Almaden Research Center, D2K13E, 650 Harry Road, San Jose, California 95120, USA \\ ${ }^{*}$ Corresponding author: fbaida@univ-fcomte.fr
}

\begin{abstract}
Using the $N$-order finite-difference time-domain (FDTD) method, we show that optical resonances of the bowtie nanoaperture (BNA) are due to the combination of a guided mode inside the aperture and Fabry-Perot modes along the metal thickness. The resonance of lower energy, which leads to the well-known light confinement in the gap zone, occurs at the cutoff wavelength of the fundamental guided mode. No plasmon resonance is directly involved in the generation of the light hot spot. We also define a straightforward relationship between the resonance wavelengths of the BNA and its geometrical parameters. This brings a simple tool for the optimization of the BNA design. (C) 2010 Optical Society of America
\end{abstract}

Recently, bowtie nanoapertures (BNAs) have been proposed as an alternative solution to bowtie nanoantennas $[1,2]$ for efficiently concentrating light down to the nanoscale level [3-5]. It has been shown that these two kinds of nanostructure are both able to resonantly create dipolelike electric-field concentrations in their gap zones when they are excited with a free-space propagative wave linearly polarized along their main axis [6]. BNAs have been successfully used as nanometer-sized light sources for nanolithography [6] and near-field optical imaging [7]. Deeply understanding the resonance properties of such structures is highly desirable for improving their optical performances and design. A first explanation of the origin of the BNA resonance has been proposed in [8]. The authors assert that the ability of the BNA to generate a hot spot in the gap region is due to the excitation of a plasmon resonance of the structure. They showed that the wavelength of this resonance is defined by the metal nature and not by the thickness of the metal layer.

In this Letter, we propose an alternative explanation of the optical properties of the BNA. For this purpose, we demonstrate that a vertical guided mode inside the structure, rather than a localized plasmon resonance, is responsible for the light confinement ability of the BNA. We also define an analytical expression between the resonance wavelengths of the BNA and its gap width, lateral size, and metal kind.

Let us consider the schematic of the BNA presented in Fig. 1, where the geometrical parameters are defined in the caption. When illuminated at normal incidence, such

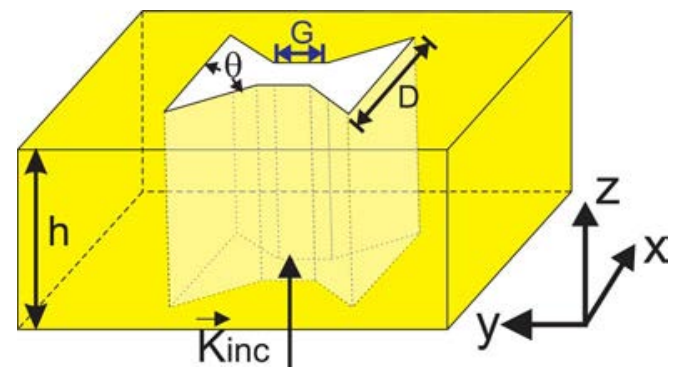

Fig. 1. (Color online) Scheme of the BNA. The BNA geometrical parameter dimensions are defined by the lateral size $D$, the gap size $G$, the bow angle $\theta$, and the metal thickness $h$. a BNA presents an enhanced near-field light intensity around the gap for specific wavelength values. This phenomenon strongly depends on the polarization of the incident beam. In fact, only $x$ polarization (see Fig. 1) leads to this enhancement. A typical example of a near-field spectrum of a BNA is presented in Fig. 2, where the device is illuminated by a linearly polarized plane wave.

One can see a succession of peaks corresponding to a light enhancement. As mentioned in [8], the position of all the peaks depends on the metal thickness, except the highest wavelength one, here named $\mathrm{FP}_{0}$ (see Fig. 2). In fact, we see in Fig. 3 that its position is almost independent of the metal thickness, especially for thick metallic films. That is why this peak has been attributed to a plasmon resonance, while the other peaks $\left(\mathrm{FP}_{i}, i>0\right)$ were related to a Fabry-Perot phase matching between signals travelling along the aperture in the metal thickness direction (in the upward and downward directions).

In the following we will demonstrate that all these peaks have the same origin: the excitation of the fundamental guided mode of the infinitely long bowtie waveguide. The

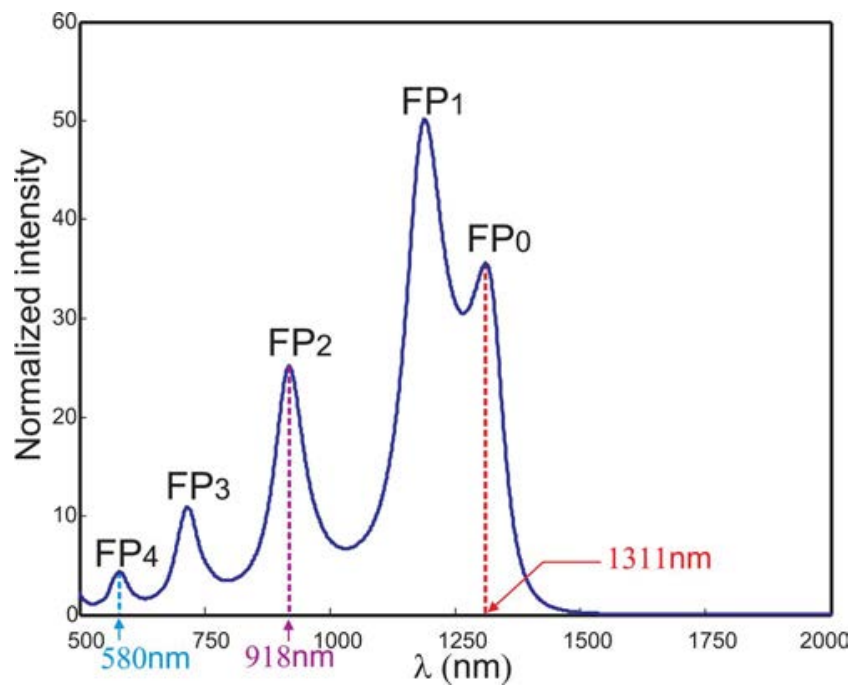

Fig. 2. (Color online) Normalized electric-field intensity spectrum calculated (3D-FDTD simulations) in the near field at $5 \mathrm{~nm}$ beyond the gap. We set $D=275 \mathrm{~nm}, \theta=45^{\circ}, G=55 \mathrm{~nm}$, and $h=800 \mathrm{~nm}$. 


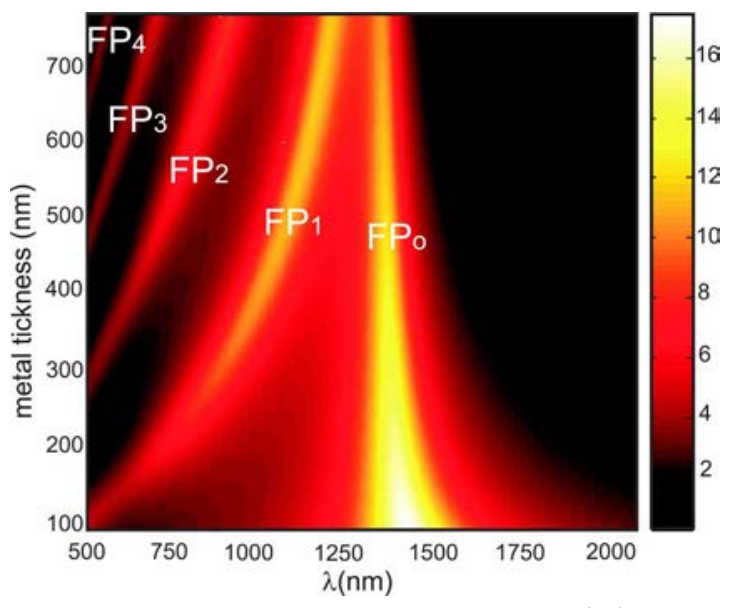

Fig. 3. (Color online) Transmission spectrum $(|E|)$ of the BNA as a function of the metal-layer thickness obtained through homemade 3D-FDTD code $\left(D=275 \mathrm{~nm}, \theta=45^{\circ}, G=55 \mathrm{~nm}\right.$, and $h$ varies from 100 to $770 \mathrm{~nm})$.

transmission peaks are then defined by a Fabry-Perot phase-matching condition that is always verified at the cutoff wavelength, which is independent of the metal thickness. In fact, for this specific value of the wavelength, the effective index of the mode falls to zero. In addition, higher harmonics $\left(\mathrm{FP}_{i}, i>0\right)$ can appear according to the thickness value. This phenomenon is similar to the one observed in the case of the enhanced optical transmission obtained through annular aperture arrays [9]. To clearly point out this effect, let us consider the infinitely long bowtie waveguide presented in Fig. 4, where both gap and external sides are squares $\left(\theta=45^{\circ}\right)$. Our purpose is to calculate the lowest-order guided modes of this waveguide. An $N$-order finite-difference time-domain (FDTD) algorithm including a Drude model to describe the metal dispersion is used to determine the cutoff frequency of the guided modes [9]. The cutoff wavelengths of the TE guided modes (only $E_{x}, E_{y}$, and $H_{z}$ are not zero) are obtained by determining the spectral density for $k_{z}=0$. The principle of this FDTD code is based on the excitation of

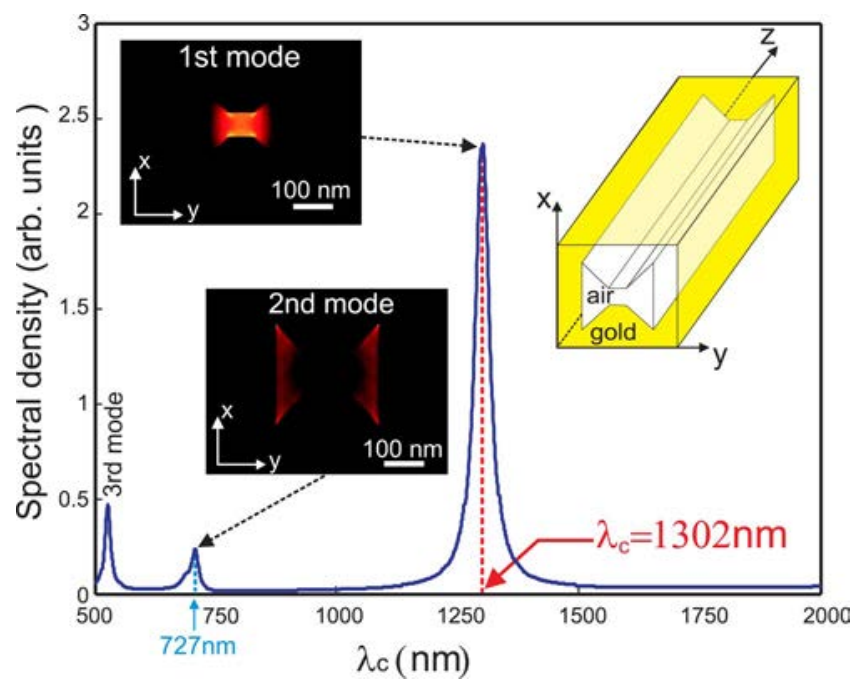

Fig. 4. (Color online) Spectral density of the infinitely long bowtie waveguide made in gold with the same geometrical parameters of Fig. 2. Insets, intensity distributions $\left(|E|^{0.8}\right)$ of the two first modes.
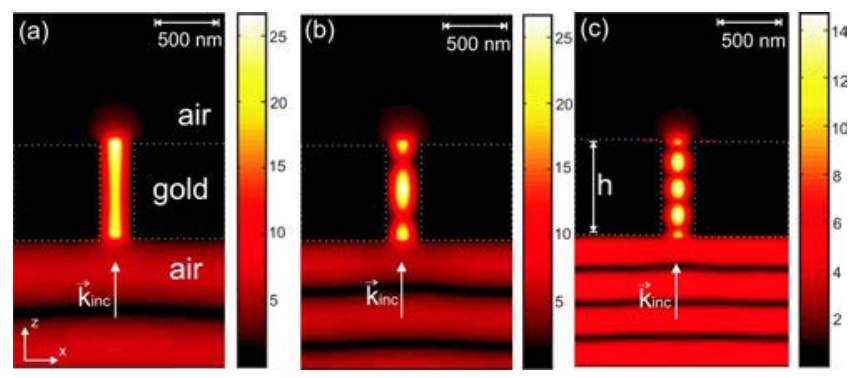

Fig. 5. (Color online) Intensity distributions $\left(|E|^{0.4}\right)$ in the transversal plane $x-z$ : (a) $\lambda=1311 \mathrm{~nm}$, (b) $\lambda=918 \mathrm{~nm}$, and (c) $\lambda=580 \mathrm{~nm}$ corresponding to the $\mathrm{FP}_{0}, \mathrm{FP}_{2}$, and $\mathrm{FP}_{4}$ peaks of Fig. 2, respectively.

the structure by all the possible frequencies (depending on the desired spectral range) and to follow the temporal evolution of the spectral density until the guided modes stabilize. The resulting spectrum contains several peaks corresponding to the different eigenmodes of the structure for a given value of the propagation constant $\left(k_{z}\right)$. An example of such a spectral density corresponding to a specific BNA is illustrated in Fig. 4 for the three first eigenmodes. Note that a dispersion diagram can also be determined by varying the $k_{z}$ value. From this last figure, one can see that the fundamental mode has a cutoff wavelength that corresponds to the same position of the $\mathrm{FP}_{0}$ peak of the spectrum shown in Fig. 2. This result is confirmed by other simulations where the geometrical parameters of the infinitely long bowtie waveguide are changed. The square modulus of the electric field associated with the first two modes is presented in Fig. 4. It is clearly shown that only the fundamental mode $(v)$ corresponds to a light confinement around the gap, while the second mode, which is degenerated and occurs at $\lambda=$ $727 \mathrm{~nm}$, has an intensity node at the center of the aperture. The behavior of a Fabry-Perot resonance of the other peaks $\left(\mathrm{FP}_{i}, i>0\right)$ is demonstrated in Fig. 5, where longitudinal light distributions ( $x-z$ plane) of the electric intensity are presented for wavelengths corresponding to the spectral positions of three peaks of Fig. 2. Note here that full 3D-FDTD simulations are necessary to obtain these results (Fig. 5) because they correspond to a single, isolated BNA, contrarily to the simulations in [8], where a biperiodic array of BNA is considered. We emphasize here that, comparing to a cylindrical aperture with the same dimensions, the BNA structure exhibits a much larger cutoff wavelength of the fundamental guided mode $\left(\lambda_{c}^{\text {cylinder }}=565 \mathrm{~nm}\right.$ and $\left.\lambda_{c}^{\mathrm{BNA}}=1302 \mathrm{~nm}\right)$. One can clearly see a uniform intensity distribution of the $\mathrm{FP}_{0}$ mode along the metal thickness [Fig. 5(a)]. This confirms the very small value of the guided mode effective index at this wavelength [10]. One node appears in the middle of the cavity for $\mathrm{FP}_{1}$ wavelength, two nodes for $\mathrm{FP}_{2}$ [Fig. 5(b)] wavelength, and so on.

Table 1. Parameters of Eq. (1) for the Five Metals

\begin{tabular}{lcrrrr}
\hline Metal & \multicolumn{1}{c}{$\mathrm{Au}$} & \multicolumn{1}{c}{$\mathrm{Ag}$} & \multicolumn{1}{c}{$\mathrm{Al}$} & \multicolumn{1}{c}{$\mathrm{Cu}$} & \multicolumn{1}{c}{$\mathrm{W}$} \\
\hline$\alpha$ & 6.80 & 6.82 & 6.77 & 6.82 & 12.47 \\
$-\beta$ & 161 & 155.65 & 150.46 & 163.8 & -40.40 \\
$-\delta$ & 0.58 & 0.59 & 0.56 & 0.59 & 1.82 \\
$\gamma(\mathrm{nm})$ & 686.56 & 673.24 & 496.53 & 751.77 & -160.97 \\
\hline
\end{tabular}



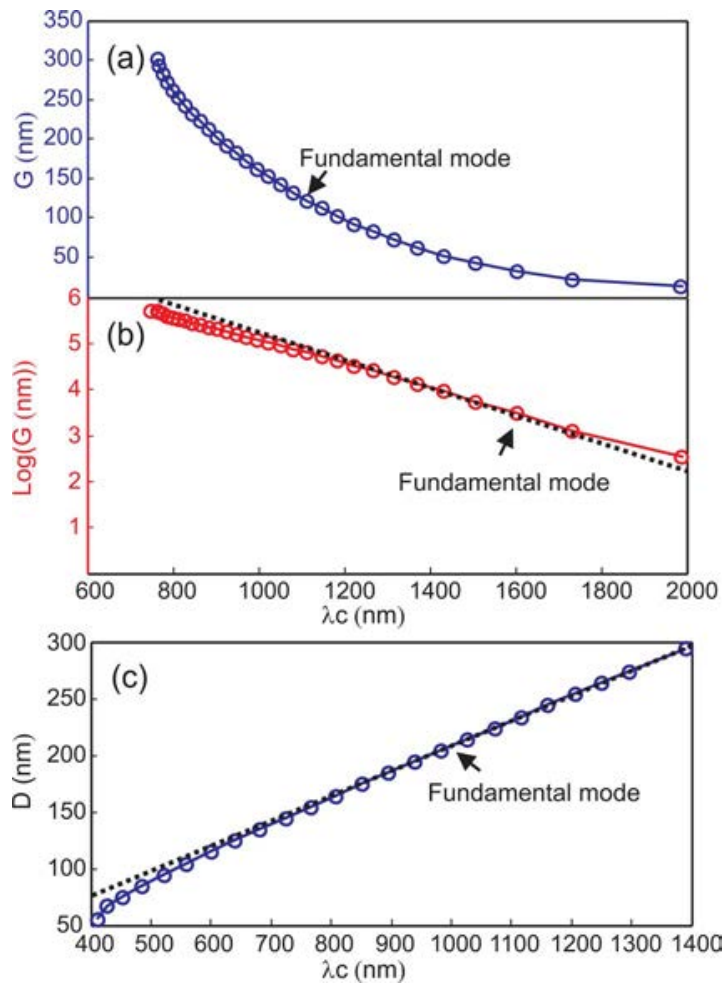

Fig. 6. (Color online) Cutoff wavelength of the fundamental mode (a) as a function of $G$ and (b) as a function of the natural logarithm of $G$, when $D=305 \mathrm{~nm}$. (c) Cutoff wavelength of the fundamental mode as a function of $D$ when $G$ is fixed to $55 \mathrm{~nm}$. The dashed curves in (b) and (c) correspond to Eq. (1) with parameters given in Table 1.

Consequently, it is clear that only the fundamental mode of the BNA is involved in the light confinement that occurs around the gap area. This is why, in the rest of this Letter, we will focus our study on this mode.

Afterward, a modal study is performed using a $\mathrm{N}$-order FDTD algorithm. As in [8], five different metals (Ag, Au, $\mathrm{Al}, \mathrm{Cu}$, and $\mathrm{W}$ ) are taken into account through a Drude model that is given in Table 1 of [8].

Figure 6(a) presents the cutoff wavelength of the fundamental mode as a function of the gap size $(G)$ for a bowtie waveguide made in gold and for $D=305 \mathrm{~nm}$. We see that the cutoff wavelength of the fundamental mode depends strongly on the gap size. Note also that similar behaviors are obtained for the other metals, although the curves show a redshift in the case of $\mathrm{Cu}$ and $\mathrm{W}$, and a blueshift in the case of $\mathrm{Ag}$ and $\mathrm{Al}$ with respect to the gold. Figure 6(b) gives the same curves as a function of the natural logarithm of the gap size. A linear behavior is then obtained. The same study is performed by changing $D$ for a fixed value of $G=55 \mathrm{~nm}$, and the results are presented in Fig. 6(c). Accordingly, a relationship between the cutoff wavelength and the ordered pair $(G, D)$ can be established by

$$
\lambda_{c}(G, D)=\alpha D+\beta \ln (G)+\delta D \ln (G)+\gamma,
$$

where $\lambda_{c}, G$, and $D$ are expressed in nanometers. To determine the parameters $(\alpha, \beta, \delta$, and $\gamma)$ in Eq. (1), the cutoff wavelength of the fundamental mode is calculated from four different couples $(G, D)$. By proceeding in the same way, we find the parameters (Table 1) of Eq. (1) for the other metals. It is obvious that this relation is valid only for $G \in[25 \mathrm{~nm}-225 \mathrm{~nm}]$ and $D \in[115 \mathrm{~nm}-300 \mathrm{~nm}]$, corresponding to our domain of interest, which is imposed by the technological processes of fabrication and the desired resonance wavelength of the BNA.

In summary, we have demonstrated that the light confinement obtained in front of a BNA is linked to the excitation, at its cutoff wavelength, of a guided mode inside the aperture and, specifically, in the gap part of the aperture. No localized plasmon resonance is explicitly involved in this phenomenon. A simple analytical expression is found to govern the value of the cutoff wavelength of this fundamental mode. This brings a very simple and direct tool for the optimization of the BNA design.

This work is funded by the Agence Nationale de la Recherche under contract ANR-NANO-07-036. It is also supported by the Pôle de Compétitivité Microtechniques.

\section{References}

1. T. Kalkbrenner, U. Hakanson, A. Schadle, S. Burger, C. Henkeland, and V. Sandogdhar, Phys. Rev. Lett. 95, 200801 (2005).

2. D. P. Fromm, A. Sundaramurthy, P. J. Schuk, G. Kino, and W. E. Moerner, Nano Lett. 4, 957 (2004).

3. K. Sendur and W. Challener, J. Microsc. 210, 279 (2003).

4. E. X. Jin and X. Xu, Appl. Phys. Lett. 86, 111106 (2005).

5. E. X. Jin and X. Xu, Appl. Phys. B 84, 3 (2006).

6. L. Wang and X. Xu, J. Microsc. 229, 483 (2008).

7. R. Guo, E. C. Kinzel, Y. Li, S. M. Uppuluri, A. Raman, and X. $\mathrm{Xu}$, Opt. Express 18, 4961 (2010).

8. H. Guo, T. P. Meyrath, T. Zentgraf, N. Liu, L. Fu, H. Schweizer, and H. Giessen, Opt. Express 16, 7756 (2008).

9. F. I. Baida, D. V. Labeke, G. Granet, A. Moreau, and A. Belkhir, Appl. Phys. B 79, 1 (2004).

10. F. I. Baida, A. Belkhir, D. V. Labeke, and O. Lamrous, Phys. Rev. B 74, 205419 (2006). 